\title{
The Bright Spot and Growth Process of the 1995 Hyogo-ken Nanbu Earthquake
}

\author{
Yasuhiro Umeda, ${ }^{1, *}$ Teruo Yamashita, ${ }^{2}$ Kiyoshi Ito, ${ }^{1}$ and Haruo Horikawa ${ }^{1}$ \\ ${ }^{1}$ Disaster Prevention Research Institute, Kyoto University, Uji 611, Japan \\ ${ }^{2}$ Earthquake Research Institute, the University of Tokyo, Tokyo 113, Japan
}

\begin{abstract}
A clear aftershock gap was found in the central portion of the belt shaped aftershock area of the 1995 Hyogo-ken Nambu earthquake. We term this gap an "earthquake bright spot." In this paper, the rupture growth process of the main shock is discussed in the framework of the earthquake bright spot model. The resultant process is as follows: The rupture initiated at the depth of $14 \mathrm{~km}$, which was the bottom of the seismogenic zone, and it propagated in a semicircular direction. The early stage of rupture was very slow with small dislocation. After about $4 \mathrm{~s}$, it accelerated by successive fault step-over and some subfaults were produced in the confined region, the "bright spot." The preliminary duration of $4 \mathrm{~s}$ satisfies Umeda's empirical formula, which expresses the relationship between the nucleation time and earthquake magnitude. Powerful high-frequency waves of $0.5-1.5 \mathrm{H} z$ were concentrically radiated from the bright spot within a short time. After about $9 \mathrm{~s}$, just beneath Kobe City, predominant long-period waves of 5-6s were produced by moment release from smooth dislocation of a fault.
\end{abstract}

\section{Introduction}

A destructive earthquake of $M 7.2$ struck the southern area of Hyogo Prefecture on January 17 , 1995. The quake calused severe damage in Kobe and adjacent cities. At least two faults with slightly different strike were formed by this quake. The faults had a step-over of $4 \mathrm{~km}$ at the epicenter, but these ruptures had the same right-lateral strike-slip motion with some dip-slip component. Surface slippage extending over $11 \mathrm{~km}$ was found on the active Nojima fault on Awaji Island (Geological Survey of Japan, 1995; Awata e'l al., 1995), but no slippage could be found on the Rokko fault system near Kobe City.

Aftershocks spread over about $70 \mathrm{~km}$, extending N50-55'E (Research Center for Earthquake Prediction (RCEP), DPRI, Kyoto University, 1995; Osaka District Meteorological Observatory, JMA and Earthquake Prediction Information Division, JMA (JMA), 1995). In the aftershock distribution, a clear gap was found near the hypocenter of the main shock just under Akashi Strait. We term this aftershock gap an "earthquake bright spot."

Broad-band strong-motion seismometers success- fully detected three different rupture stages: preliminary small rupture phases, powerful secondary high-frequency waves, and rather long-period third waves.

Some authors have discussed the rupture process of this earthquake using inversion methods (e.g., Kikuchi, 1995; Ide et al., 1996; Horikawa et al., 1996). Some of them suggest three stages of rupture or three events of relatively large moment release. Most waveform inversion methods, however, are limited to discuss the generation of high-frequency waves, 0.5 or $1.0 \mathrm{~Hz}$. In this paper, we discuss the generation of powerful high-frequency waves based on various data sets including seismological, geological and geodetic observations. The fault-step is especially important for the generation of this type of wave.

\section{Spatial Evidence of the Bright Spot}

\subsection{Aftershock gap}

Immediately after the main shock, GROUPS-95 (Geophysical Research Organized by Universities for Prediction Seismology in 1995) quickly deployed 27 temporary seismological stations in the source area of southern Hyogo Prefecture. Using a por-

Received July 14. 1995; Accepted April 22, 1996

* To whom correspondence should be addressed. 

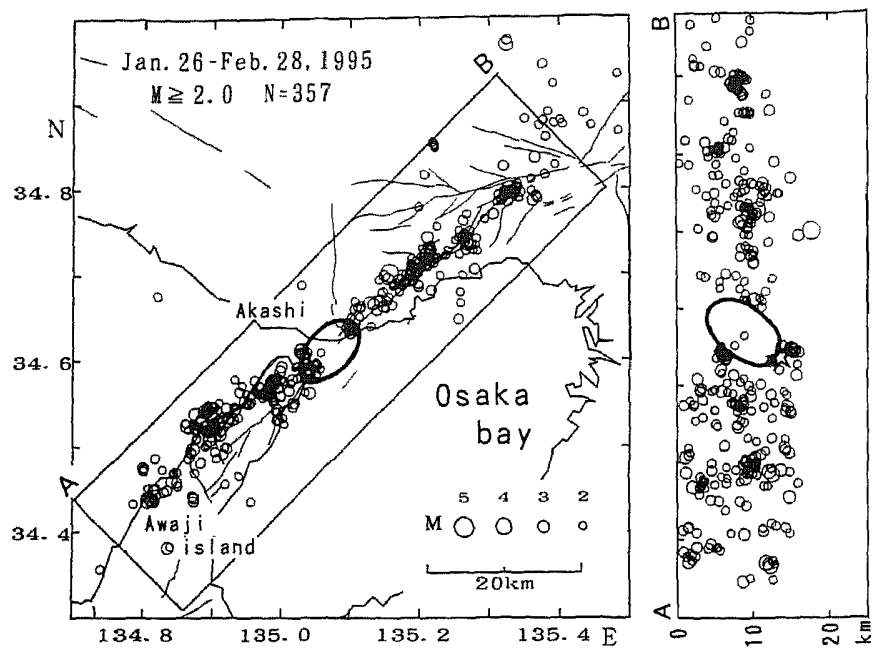

Fig. 1. Aftershock distribution (February 10-28, 1995). Star indicates the hypocenter of the main shock determined by JMA. Ellipse shows the earthquake bright sopt.

table telemetering system, seismic wave data were transmitted to the observation center which was set temporarily at RCEP. The data from 29 permanent stations were also transferred to this center through Internet connection. The processing system at the temporary center automatically located hypocenters in real time (Hirata et al., 1996). The precise aftershock distribution shown in Fig. 1 was redetermined from manually picked $\mathrm{P}$ and $\mathrm{S}$ phases. The hypocenter, in terms of the nucleation point of the main shock, was determined by JMA and is indicated by the large star in Fig. 1. The aftershock area extends $70 \mathrm{~km}$ trending $\mathrm{N} 50-55^{\circ} \mathrm{E}$, which is consistent with the fault-plane solution obtained by JMA (1995). The aftershock activity is very low around the nucleation point. Umeda (1992) called this kind of aftershock gap an "earthquake bright spot." As shown in Fig. 1, the bright spot occupies an elliptical region near the hypocenter. The ellipsoidal volume of the bright spot is $11 \times 7 \mathrm{~km}$ and $4 \mathrm{~km}$ thick.

\subsection{Subfault under Akashi Strait}

On Awaji Island, a maximum surface net slippage of $2.4 \mathrm{~m}$ was found on the Nojima fault (Awata $e t$ al., 1995). Although no slippage could be found on the surface of the Rokko fault system such as the Yokoo-yama and Suma faults, the leveling results strongly suggest dislocation at deep portion of these faults. The inserted numerals in Fig. 2 show the leveling results measured by the Geographical Survey Institute (1995). The turning points of upheaval and subsidence can be seen on the Yokooyama and Suma faults. It is certain that a deep portion in these two faults was dislocated by the earthquake.

The Akashi Strait Bridge, currently under construction on Akashi Strait, played the role of a long-span strainmeter (Fig. 2). In an informal report from Honshu-Shikoku Road Corporation, the displacement of two main towers $(b$ and $c$ in Fig. 2) and two bases of the bridge (a and d in Fig. 2) were obtained by GPS measurements. The main tower (c) and the base of the bridge (d) on the Awaji side were relatively displaced by 130 and $140 \mathrm{~cm}$ southwest, respectively, against those on the Akashi side. The different vectors of two points ( $c$ and $d$ ) suggest that there are at least two dislocated subfaults under the seabed of Akashi Strait as shown by the two thick broken lines in Fig. 2 .

Although, new breakage could not be found on the seabed in Akashi Strait, a new fault (e in Fig. 2) formed by the Hyogo-ken Nanbu earthquake was found on the seabed to the east of Akashi Strait by acoustic exploration (Iwabuchi et al., 1995, Hydrographic Department Maritime Safety Agency, 1995). The Yokoo-yama and Suma faults in Kobe, and some unnamed faults under Akashi Strait, might have undergone dislocation at a deep portion.

Some subfaults were produced by fault-step, and 


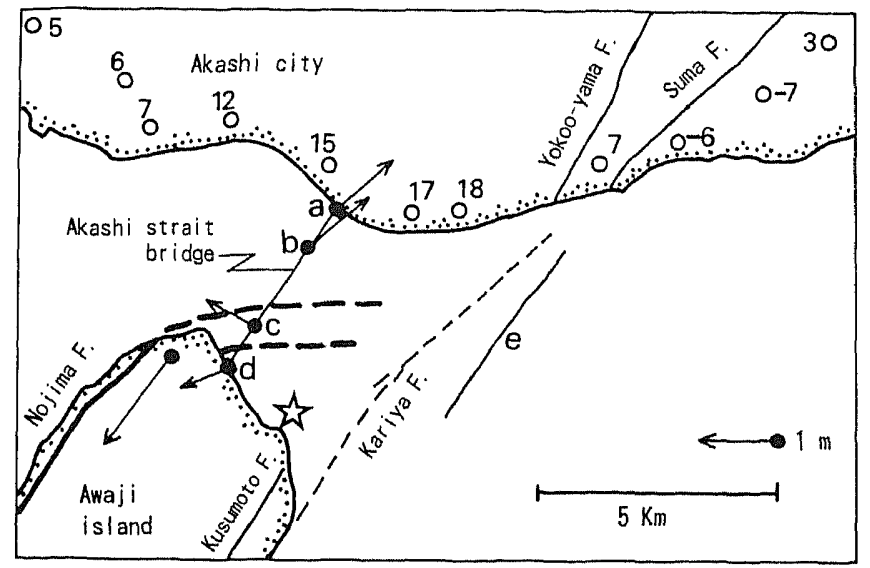

Fig. 2. Subfaults around Akashi Strait, a: base of bridge in Akashi; b: main tower in Akashi; $c$ : main tower in Awaji; $d$ : base of bridge in Awaji; e: new fault on the seabed. The two thick broken lines are assumed faults. Numerals indicate the leveling results.

their parallel or echelon arrangements constituted a fault zone with a width of about $4 \mathrm{~km}$ under Akashi Strait. This region coincides with the aftershock gap described in the previous section as the earthquake bright spot.

\section{Evidences of the Bright Spot Seen on Seismo- grams}

\section{I Powerful waves radiated from the bright spot}

Strong-motion seismometers were distributed in the source area and in short focal distances by the Committee of Earthquake Observations and Research in the Kansai Area and RCEP, DPRI, Kyoto Univ. The instrument, called VSE, has a flat response for ground velocity in the frequency range from 0.025 to $70 \mathrm{~Hz}$. The seismometers recorded numerous seismograms which revealed the rupture process of the main shock.

The seismograms recorded at Kobe University, which is situated just over the fault, are shown in Fig. 3(a). The initial phase rises up very slowly and the predominant high-frequency S-waves suddenly appear. The $\mathrm{S}$-waves with the frequency range of $0.5-1.4 \mathrm{~Hz}$ reach a maximum velocity of up to $0.85 \mathrm{~m} / \mathrm{s}$ in NS component and then steeply diminish after a duration of about $5 \mathrm{~s}$. These powerful waves, indicated by the shaded bar in Fig. 3, caused severe damage to housing and other structures. This kind of powerful wave was observed on the seismograms recorded at Abuyama (Fig. 3(b)). The seismometers at Abuyama, which is situated on the nodal line of the fault plane solution, were installed on rock in an observation tunnel. The characteristics of the predominant $S$-waves are similar to those recorded in Kobe; that is, high frequency of $0.8-1.5 \mathrm{~Hz}$ and a short duration of less than $3 \mathrm{~s}$.

Powerful $\mathrm{S}$-waves were radiated from the early rupture stage and diminished in a short time. This kind of wave is concentrically radiated from a small confined region near the nucleation point. However, it is difficult to produce powerful high-frequency waves from only one fault plane. As described in the previous section, some subfaults were formed in the bright spot and they stepped over successively out of the preceding fault plane. To explain the powerful waves, it is plausible that the superposition of impulsive wavelets radiated from such subfaults in the bright spot.

Since the waveform inversion by Horikawa et al. (1996) utilized seismograms passed through a band-pass filter having the cut off frequency of $0.5 \mathrm{~Hz}$, it is difficult to specify the region producing high-frequency waves. Kakehi et al. (1995) estimated the region which generated high-frequency waves by the envelope inversion method using acceleration seismograms. Their results show that most of the high-frequency waves are radiated from a somewhat southwest portion just over the hypocenter. Although it includes the southwest end of the bright spot, it shifts slightly to the southwest. 

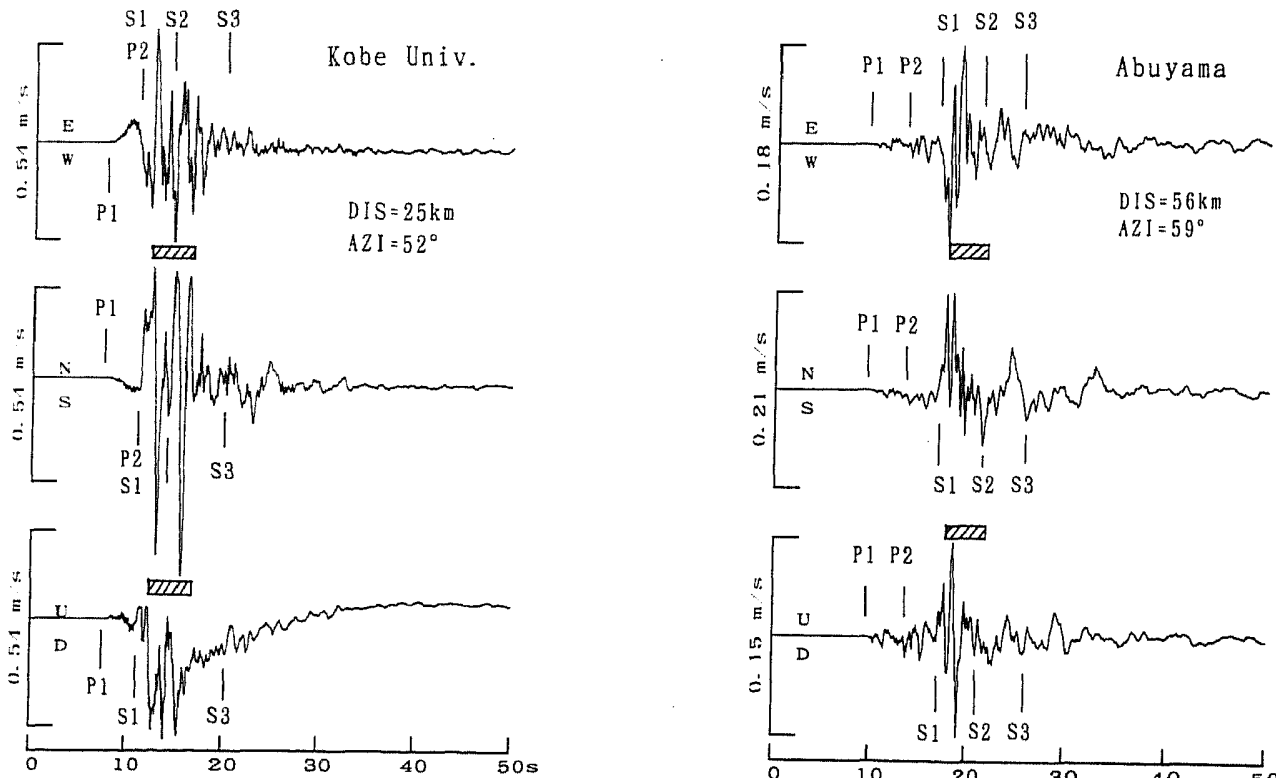

(a)

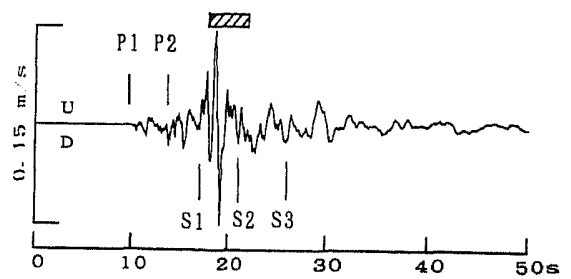

(b)



P1 P2 P3 S1 S2 S3 $\quad$ AZI $=296^{\circ}$

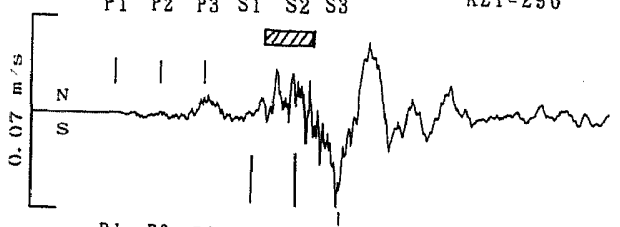

$\begin{array}{llllll}\text { P1 } & \text { P2 } & \text { P3 } & \text { S1 } & \text { S2 } & \text { S3 }\end{array}$

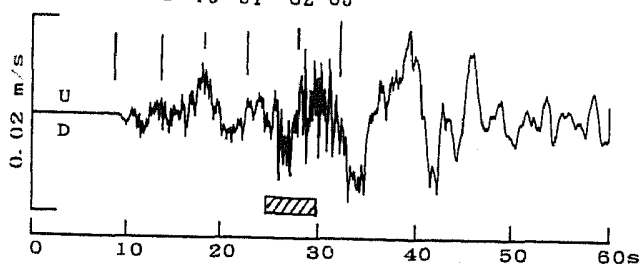

(c)

Fig. 3. (a) Seismograms recorded by VSE at Kobe University $\left(34.725^{\circ} \mathrm{N}, 135.240^{\prime \prime} \mathrm{E}\right)$. Vertical component clipped at P2 and S1 phase. Shaded bars indicate the duration of powerful highfrequency waves. (b) Seismograms recorded by VSE at Abuyama $\left(34.860^{\circ} \mathrm{N}, 135.574^{\circ} \mathrm{E}\right)$. (c) Seismograms recorded by VSE at Qume $\left(35.089^{\circ} \mathrm{N}, 133.849^{\circ} \mathrm{E}\right)$.

\subsection{Nucleation Phase}

Very low amplitude in the early stage, which might have been radiated from the initial small rupture, was recorded at stations of various distances and azimuthes. After approximately $4 \mathrm{~s}$ from $\mathrm{P} 1$ onset, a clear, secondary onset of $\mathrm{P} 2$ is

found on almost all of the seismograms. Since the seismograms at Kobe University are on the fault (Fig. 3(a)), unfortunately, P2 and S1 arrived are at the same time, and their measurements are superimposed. The separation of these phases is good in the far-field data rather than near-field data. 


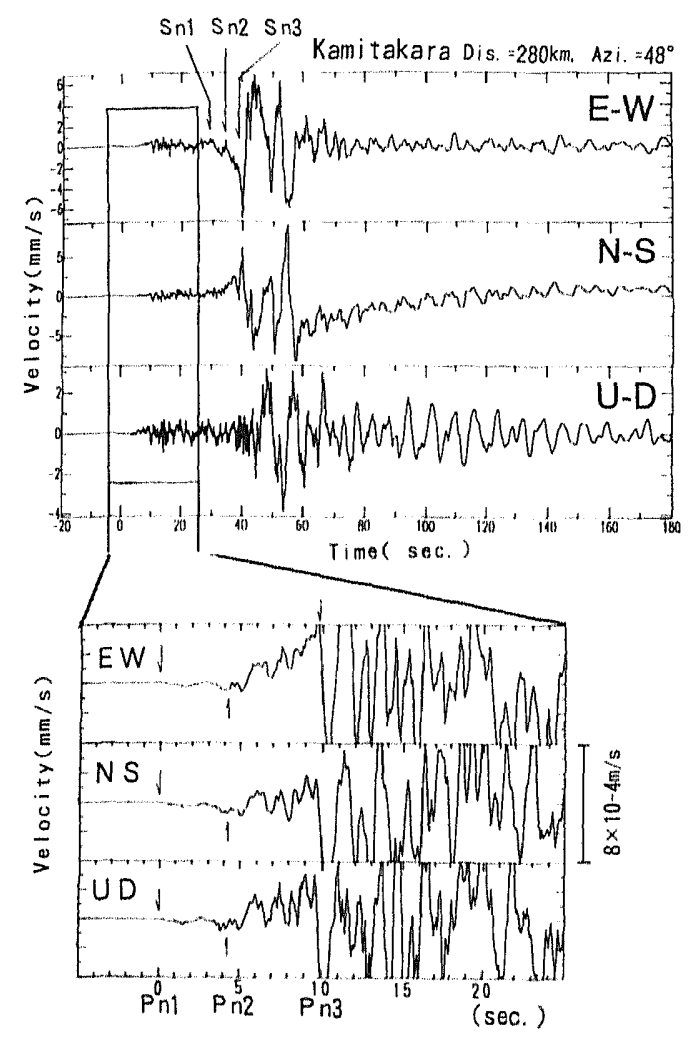

Fig. 4. Seismograms recorded by STS at Kamita$\operatorname{kara}(36.280 \mathrm{~N}, 137.327 \mathrm{E})$.

The three full components traces and on enlarged P-wave portion of the seismogram recorded by the STS seismometer at Kamitakara, of which the focal distance is $280 \mathrm{~km}$, are shown in Fig. 4. three phases of $\mathrm{Pn} 1, \mathrm{Pn} 2, \mathrm{Pn} 3$ and $\mathrm{Sn} 1, \mathrm{Sn} 2, \mathrm{Sn} .3$ can be seen. In the lower figure, the durations of the low-amplitude and low-frequency waves can be seen initially for about $4 \mathrm{~s}$. The arrival time of Pn2 and that of direct P2 phase are nearly the same time at Kamitakara. The onset and polarity of the second phase $(\mathrm{Pn} 2, \mathrm{Sn} 2)$ are somewhat vague. However, about $4 \mathrm{~s}$ later, the amplitudes rapidly increase and high-frequency waves predominate. This kind of $\mathrm{Pn} 2$ phase was also identified on the seismograms from the Abuyama and Qume stations (Fig. 3(b), (c)).

The duration from rupture initiation to faulting acceleration is called the nucleation time, and the (P1-P2) phase is called the nucleation phase. Umeda and Yamashita (1994) found that the earthquake magnitude was proportionate to the nucleation time (Fig. 5), and he proposed the relationship as follows:

$$
\log (\mathrm{P} 1-\mathrm{P} 2)=0.55 M-3.4 .
$$

The nucleation time of $4 \mathrm{~s}$ and earthquake magnitude ( $M$ 7.2) of the Hyogo-ken Nanbu earthquake satisfy this relationship.

\subsection{Third rupture and long-period waves}

According to the report by Horikawa (1996), some amount of moment was released just under Kobe City from 7 to $11 \mathrm{~s}$ after the rupture initiation. About $9 \mathrm{~s}$ after rupture initiation, the third event phase (P3, S3) can be identified on the seismograms from Qume and Kamitakara (Figs, 3(c), 4). These waves, which may be expected from a smoothing dislocation, continued for a rather long period of $5-6 \mathrm{~s}$, and can be found on the early portion of the seismograms. This period satisfies the relationship of earthquake magnitude and predominant period. According to Kasahara's formula (Kasahara, 1957)

$$
\log T=0.51 M-2.95,
$$

the predominant period $(T)$ is $5.3 \mathrm{~s}$ for the $M 7.2$ of the Hyogo-ken Nanbu earthquake.

Kobe City was struck twice by waves of different frequencies: powerful high-frequency waves from the bright spot and low-frequency waves about $9 \mathrm{~s}$ later.

\section{Growth Process of the Hyogo-ken Nanbu Earth- quake}

\section{I Bright spot model}

Umeda (1992) proposed the bright spot model, which includes three stages of rupture as shown in Fig. 6. The first stage is rupture initiation and preliminary smooth propagation (Fig. 6 (A)). On the seismograms, it corresponds to the nucleation phase. In the second stage, the shear strain wave radiated from the faulting of the first stage excites and drives other nucleation sources distributed spatially in the seismogenic zone. Many new ruptures develop almost simultaneously within a confined region (the bright spot in Fig. 6 (B)). Adjacent subfaults within the bright spot, however, restrain their own development because of their strong interaction (Yamashita and Umeda, 1994). In the third stage, one of subfaults, which may be at the outermost side of the bright spot, shakes off the restrictions from the other subfaults and breaks through as a final fault (Fig. 6 (C)). Many high- 


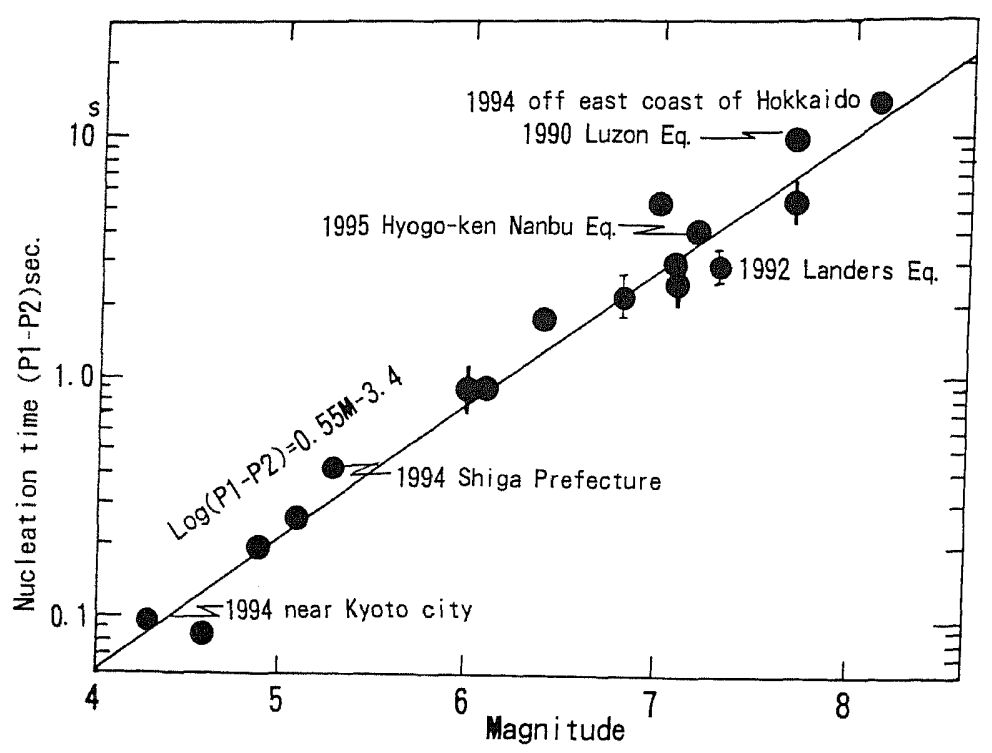

Fig. 5. Nucleation time as a function of earthquake magnitude. The base figure is taken from Umeda (1992).

frequency wavelets are concentrically radiated from massive subfaulting in the bright spot. The superimposing of these wavelets produces powerful highfrequency waves. Since the local stress in the bright spot is completely released by massive subfaulting, aftershocks no longer occur in this spot.

\subsection{Fault-step and high-frequency waves}

The rupture growth process of the Hyogo-ken Nanbu earthquake can be explained by the framework of the bright spot model. The planar strike using the fault mechanism solution determined from the initial Pl onset coincides with the fault strike (232) of the assumed fault on the Kobe side. As shown in the vertical cross section inserted in Fig. 7, the rupture started from the bottom of the fault on the Kobe side (1) in Fig. 7) and propagated in a semicircular direction.

Shortly after rupture initiation, it is possible that fault-step began and secondary new ruptures were successively induced within the dotted ellipse shown by (2) in Fig. 7. About $4 \mathrm{~s}$ later, the faulting accelerated. Powerful waves were produced by superimposition of the high-frequency wavelets emitted from the subfaulting. The duration of these predominant high-frequency was terminated within 3-5 s. Almost of the faults were steeply decelerated by these interaction in the bright spot. The most out side of fault group, in this case Nojima fault, passed

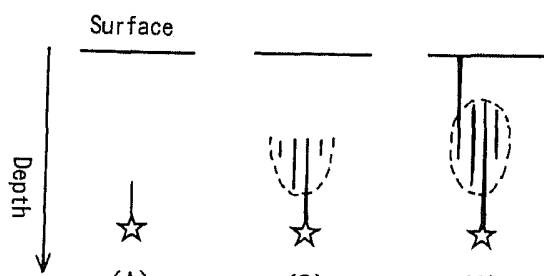

(A)

(B)

(C)

Fig. 6. Three stages of rupture growth process. (A) Preliminary rupture. (B) Fault-step and the bright spot (dotted ellipse). (C) Final fault intersecting the bright spot.

through the bright spot into a free surface. In this way, within the bright spot, the rupture stepped over from the Kobe side to the Nojima fault. The Nojima fault, which strikes $220^{\circ}$ and dips $85^{\circ}$ southeastward propagated $11 \mathrm{~km}$ to the southwest. The maximum offset of $2.1 \mathrm{~m}$ right-lateral and $1.3 \mathrm{~m}$ southeast upward was measured on the surface (Awata et al., 1995).

\subsection{Branching of the fault end}

The earthquake fault in on Kobe side did not break the earth's surface. It smoothly propagated and dislocated in the deep portion of the seismogenic zone (Horikawa et al., 1996; Meteorological Research Institute, 1995). Almost all portions of the assumed fault strike shown in Fig. 7 coincide with 


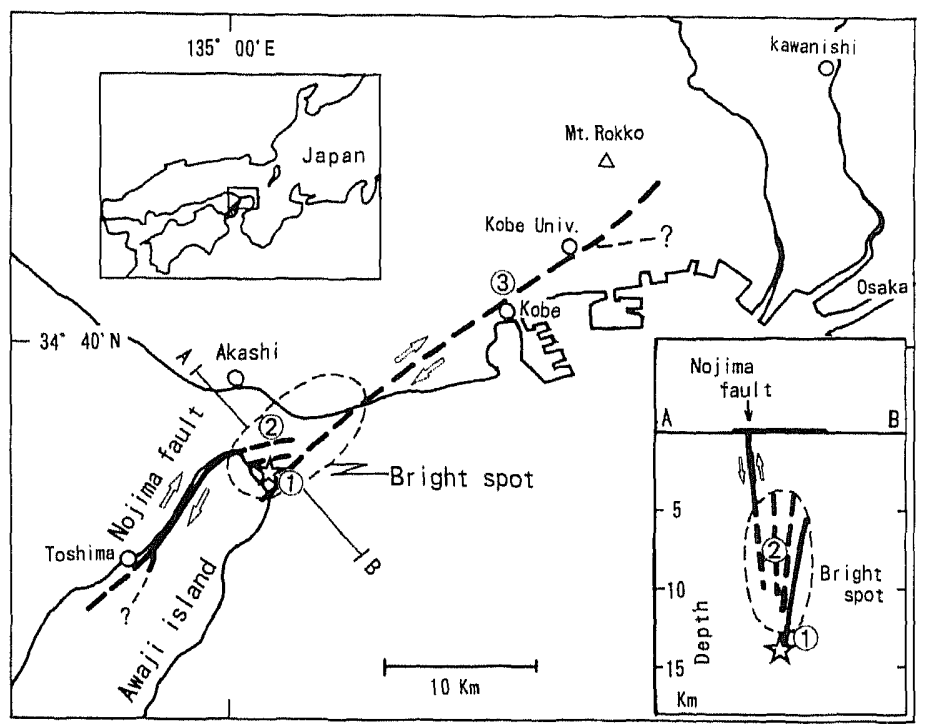

Fig. 7. Map showing the growth process model of the 1995 Hyogo-ken Nanbu earthquake. Events (1), (2), and (3) correspond to the three phases P1, P2, P3, and S1, S2, S3 on the seismograms.

both trends of aftershock distribution and the belt-shaped zone of intensity VII (JMA, 1995). At just east of Kobe University, however, each trend separates into two directions: the aftershock distribution and belt-shaped zone of intensity VII extending $N 45^{\circ} \mathrm{E}$ and $\mathrm{N} 80^{\circ} \mathrm{E}$, respectively. The former and latter trends coincide with the Gosukebashi and Ashiya faults, respectively. It is quite possible that the final stage of faulting branched off along two existing faults as shown by the thin broken lines in Fig. 7.

The surface trace of the Nojima fault also branched off at the southwest end. According to the analysis using geodetic data such as GPS and leveling (Hashimoto, 1995), the deep portion of the Nojima fault extended further southwest to about $5 \mathrm{~km}$ from Toshima City as shown by the thick broken line in Fig. 7. Although the length of branching traces on the surface was only $1 \mathrm{~km}$ or so, the dislocation of the deep portion might possibly extend further as shown by the thin broken line in Fig. 7.

\section{Summary and Discussion}

The rupture of the Hyogo-ken Nanbu earthquake started at the bottom of a seismogenic zone. In the early stage, the faulting dislocated smoothly, and a little later it began successive step-over. After
$4 \mathrm{~s}$, it accelerated and formed multiple subfaults within a confined region under the Akashi Strait. The nucleation time of $4 \mathrm{~s}$ and earthquake magnitude of 7.2 for this quake satisfies Umeda's empirical formula.

The nucleation phases (P1-P2, S1-S2) of almost all large main shocks are low frequency and low amplitude (Umeda, 1992; Ellsworth and Beroza, 1995). In the case of the Hyogo-ken Nanbu earthquake, however, nucleation amplitudes were not so small. A fairly large amount of moment might be released within $4 \mathrm{~s}$ after initiation of the nucleation process.

An aftershock gap was clearly observed under the Akashi Strait. We call this region the "earthquake bright spot." Aftershock might not occur within the bright spot because almost all of the stress in the spot is released by the formation of multiple subfaults. The powerful high-frequency waves were radiated from complex multiple ruptures in the bright spot, and terminated within only 3-5s. These waves caused severe damage to the houses and other structures.

One of the outermost step-over faults rose and broke the surface, namely the Nojima fault. The surface breakage of this fault ranged over $11 \mathrm{~km}$ in southwest direction. The rupture to the northeast direction smoothly dislocated and released some 
amount of moment just under Kobe City (3) in Fig. 7) $9 \mathrm{~s}$ after rupture initiation. From this smoothing dislocation, long-period seismic waves of $5-6 \mathrm{~s}$ were radiated. This time frame was assumed from the standard relationship of earthquake magnitude and predominant period.

The earthquake source area including Kobe City was shaken twice by waves of different frequencies: powerful high-frequency waves initially and secondary low-frequency waves about $9 \mathrm{~s}$ later. The disaster was increasingly magnified by this dual shaking.

Our examination to determine the initiation point of second and third ruptures was unsuccessful. It is very difficult to identify the arrival time of later phases such as P2, P3, S2, and S3 at all stations within $\pm 0.01 \mathrm{~s}$ or so, which may be the required accuracy for the determination of each focus.

In the bright spots of large shallow earthquakes, numerous unearthed stones and many cracks or subfaults have occasionally been found (Umeda et al., 1987). Although numerous unearthed stones were found along the Nojima fault and an assumed fault on the Kobe side (Nishizawa et al., 1995; Umeda, 1995), few unearthed stones were found on the surface immediately over the bright spot. One of the main reasons is that the bright spot of this earthquake was formed deep and did not break the earth's surface.

It is quite possible that the Nojima and Kobe-side faults branched off at each fault end. By this branching. faulting may have been decelerated and smoothly stopped.

The authors would like to thank Observations and Research in the Kansai Area and Honshu-Shikoku Road Corporation for kindly permitting the use of the seismograms and the unpublished GPS data on the Akashi Strait Bridge, respectively. We also thank Dr. T. Shibutani and two anonymous reviewers for helpful comments.

\section{REFERENCES}

Awata,Y., K. Mizuno, Y. Sugiyama, K. Shimokawa, R. Imura, and K. Kimura, Surface faults associated with the Hyogo-ken Nanbu Earthquake of 1995, Chishitsu News, 486, 16-20, 1995 (in Japanese).

Ellsworth, W. L. and G. C. Beroza, Seismic evidence for earthquake nucleation phase. Science, 268, 851-855, 1995.

Geographical Survey Institute, Crustal movements in the
Kinki district, Rep. Coord. Comm. Earthquake Predict., 54, 663-686, 1995 (in Japanese).

Geological Survey of Japan, Surface fault ruptures on Awaji Island associated with the Hyogo-ken Nanbu Earthquake of January 17, 1995, Rep. Coord. Comm. Earthq. Predict., 54, 543-546, 1995 (in Japanese).

Hashimoto M., Coseismic crustal deformations due to the 1995 Kobe Earthquake and its fault model, Chishitsu News, 490, 33-40, 1995 (in Japanese).

Hirata N., S. Ohmi, S. Sakai, K. Katsumata, S. Matsumoto, T, Takanami, A. Yamamoto, T. Nishimura, T. Iidaka, T. Urabe, M. Sekine, T. Ooida, F. Yamazaki, H. Katao, Y. Umeda, M. Nakamura, N. Seto, T. Matsushima, H. Shimizu, and Japanese University Group of Urgent Joint Observation for the 1995 Hyogo-ken Nanbu earthquake, urgent joint observation of aftershocks of the 1995 Hyogo-ken Nanbu earthquake, J. Phys. Earth, 44, 317-328, 1996.

Horikawa H., K. Hirahara, and Y. Umeda, Simultaneous inversion of geodetic and strong-motion data for the source process of the Hyogo-ken Nanbu, Japan, earthquake, J. Phys. Earth, 44, 455-471, 1996.

Hydrographic Department, Maritime Safety Agency, The distribution of faults in Osaka Bay, Rep. Coord. Comm. Earthq. Predict., 54, 753-756, 1995 (in Japanese).

Ide, S., M. Takeo, and Y. Yoshida, Source process of the 1995 Kobe earthquake: determination of spatiotemporal slip distribution by bayesian modeling, Bull. Seismol. Soc. Am., 86, 547-566, 1996.

Iwabuchi Y., S, Kasuga, and S. Kokuta, Sea bottom survey of the deformation by the Hyogo-ken Nanbu Earthquake, Chishitsu News, 490, 44-49, 1995 (in Japanese).

Kakehi Y., K. Irikura, and M. Hoshiba, Estimation of high-frequency wave radiation areas on the fault plane of the 1995 Hyogo-ken Nanbu earthquake by the envelope inversion of acceleration seismograms, $J$. Phys. Earth, 44, 505-517, 1996.

Kasahara $\mathrm{K}$., The nature of seismic origins as inferred from seismological and geodetic observations (1), Bull. Earthq. Res. Inst, Tokyo Univ., 35, 473-532, 1957.

Kikuchi M., Source process of the Kobe Earthquake of January 17, 1995, Chishitsu News, 486, 12-15, 1995 (in Japanese).

Meteorological Research Institute, Source process of the 1995 Hyogo-ken Nanbu Earthquake estimated by the analysis of near-field data of strong ground motions, Rep. Coord. Comm. Earthq. Predict., 54, 573-576, 1995 (in Japanese).

Nishizawa, O., T. Satoh, M. Sugihara, Strong ground motion near an earthquake fault inferred from upthrow of objects, Chishitsu News, 491, 9-16, 1995 (in Japanese).

Osaka District Meteorological Observatory, JMA and 
Earthquake Prediction Information Division, JMA, The 1995 Hyogo-ken Nanbu Earthquake and its aftershocks, Rep. Coord. Comm. Earthq. Predict., 54, 584-592, 1995 (in Japanese).

Research Center for Earthquake Prediction, DPRI, Kyoto Univ., Aftershock distribution of the 1995 Southern Hyogo Prefcture Earthquake determined using the JHD method, Rep. Coord. Comm. Earth. Predict., 54, 612-614, 1995 (in Japanese).

Umeda Y., A. Kuroiso, K. Ito, and I. Muramatu, High accelerations produced by the western Nagano prefecture Japan earthquake of 1984, Tectonophysics, 141, 335-343, 1987.
Umeda Y., The bright spot of an earthquake, Tectonophysics, 211, 13-22, 1992.

Umeda Y., Rupture growth process of the 1995 Southern Hyogo Prefecture Earthquake, Chishitsu News, 490, 50-55, 1995 (in Japanese).

Umeda Y. and T.Yamashita, Earthquake growth process and earthquake prediction, Proceedings of Earthquake Prediction Research Symposium (1994), National Committee Seismology, Science Council of Japan, Sesimological Society of Japan, 53-63, 1994.

Yamashita T. and Y. Umeda, Earthquake rupture complexity due to dynamic nucleation and interaction of subsidiary faults, Pageoph, 143, 89-116, 1994. 